\title{
Toward deliberative democracy: The Institutional Forum as an innovative shared governance mechanism in South African higher education
}

Authors:

Dr Anne-Marea Griffin ${ }^{1}$

Affiliation:

${ }^{1}$ International consultant on higher education management, policy advocacy and resource development in Africa

\section{Correspondence to:}

Dr Anne-Marea Griffin, 1112 Lancaster Road, Takoma Park, MD 20912,

United States of America

Tel:

+27 722177027

+1 $703559-1476$

E-mail:

amg.tangee@gmail.com agriffin@ advocacyincubator.org

DOI:

10.15249/12-1-160

\section{Keywords:}

deliberative democracy; shared governance; governance innovation; inclusion; Institutional Forum; higher education participation

\section{Abstract}

The aim of this article is to explore the effects of the Institutional Forum, a governance innovation legislated in South Africa in 1997, as a mechanism that would contribute toward the democratisation of university governance. Forums were established to confront the legacy of structured disadvantage and to reorient the educational experience towards greater horizontal accountability.

The article provides commentary on the Forum's impact vis-àvis participative ethos and deliberative democracy against the backdrop of the South African government's post-apartheid commitments. Findings reveal challenges in the Forum's make-up and implementation that are linked to its degree of influence. Ultimately, the conclusions convey perspectives on role ambiguity and conflictual power dynamics.

"The Student Representative Council (SRC) is being suffocated by the inaction of university management. ... We can't breathe." SRC Representative, March 2014

\section{Introduction}

South African higher education embodies a complex narrative. History tells of the traumatic fault lines through legislation passed in 1959 that regulated separatist principles that originated decades earlier. These divisions stemmed from efforts to create a segregated educational sector that deprived the majority black South African population of access to quality education and basic human rights derived from apartheid's cruel dictates. The trajectory of change in South African society, therefore, spanned from the depths of racist apartheid from circa 1948 to 1996, the year when arguably the 
most democratic Constitution in the world was ratified. The ideals and ideology that served as the foundation for the new South Africa were important in establishing policy priorities that shaped and restructured the landscape in light of the country's postapartheid goals of redress, access and social justice. This article analyses the journey of public universities in South Africa, with a focus on the democratisation of governance through innovative structural change that was put into place with the establishment of Institutional Forums (IFs). This change in university governance was expected to bring positive benefits to the tertiary sector. However, as the opening quote from a university student suggests, the status quo within South African universities can be characterised by pent-up dissatisfaction and anger. Among the reasons for this sentiment is the failure at what many call the deliberative democracy that was heralded in higher education legislation.

The article focuses on the extent to which stasis or change in governance has occurred within a case study university (CSU) that has had an IF in place since 1999. It will concentrate on the roles and perceptions of key participants and will study the implementation and effects of the governance arrangement that incorporated the Forum. In this way, as key authors have suggested, higher education has the potential to "include a mandate informed by a strong form of agency" (Singh, 2001:17; see also Marginson, 2006, 2011b:414; CHE, 2007:180; Sultana, 2012; Barnett, 1990; Singh, 2001, 2011; Pusser, 2006; Calhoun, 2006; Lange, 2012; Tierney, 2006a; Enders, 2012).

South African universities face significant challenges in terms of student access, diversity in academic staff, curriculum relevance and institutional climates. While progress has been made in some regard since Higher Education Act 101 in 1997, a number of important issues still need to be addressed. Moreover, the pursuit of transformation has tested the traditional bicameral governance structures within universities. The National Commission on Higher Education Report (NCHE, 1996), the Education White Paper 3: A Programme for the Transformation of Higher Education (Department of Education [DOE], 1997a) and other policy documents that originally framed a South African higher education policy, redirected the higher education system away from legislation that constrained and circumscribed the participation of the majority black population. Instead, principles of social justice, equity and democracy were stressed; all were solidly framed within the new approach of cooperative governance (NCHE, 1996).

Woven into the ideological principles that formed the basis of South African higher education was that the full participation of stakeholders was crucial. In this regard, the cooperative governance approach facilitated the development of an implementation strategy. One example of the innovative change incorporated into the transformation strategy for public universities included the governance structure, a change promulgated through the Higher Education Act of 1997 (DOE, 1997b). The establishment of IFs was based on the central role played by Broad Transformational Forums that were formed as parallel structures to University Councils and Senates during the transitional periods leading to the dismantling of apartheid in 1994 (Harper et al., 2002; Cloete \& Mohamed, 1995). The IF became a practical manifestation of the principles of participation, 
diversity of stakeholders and the promotion of discourse in ways that would bolster democratic practices within the university governance setting.

\section{Aims and objectives of the study}

The article addresses South Africa's efforts to manifest its commitment to renewed democratic governance within its universities through the establishment of IFs. The IF is a governance innovation that was established to address the legacy of the apartheid era with a formalised model of shared governance within public universities in South Africa. The IF stresses the inclusivity and deliberative dialogue of diverse constituencies on campus and places an imprint of participatory sense-making on the effort to remake the traditional bicameral construct.

The article explores the effects of this innovative mechanism on a South African university, particularly on whether and how it contributed toward the democratisation of university governance. It researches this university's attempt to foster enhanced cooperation and collaborative decision-making in order to promote a renewed institutional governance culture. In doing so, the research aims to shed light on whether IFs may have effectively changed the internal governance landscape within South African universities.

The overriding theories that provide the conceptual framework for the study are the institution's resistance to change and the social space where actors interact; the interplay between the behaviour of actors and the institutional structures that would, in effect, transform the governance of the institution. The literature review is aligned with these ideas and clear connections are drawn between existing knowledge and the investigative process.

\section{Theoretical frameworks}

The overall approach to the analysis of how or whether university governance has been transformed is supported by a variety of theorists. The overarching framework borrows certain aspects from path dependency theory and the institutional analysis and development (IAD) framework because they, respectively, (1) relate to the resilience and strategic persistence of institutions and their tendency to resist change, and (2) highlight the role that critical actors play within these institutions (Ostrom, 2011).

The literature (Ostrom, 2011) helps to frame the analysis of the research by firstly challenging the assumption that institutions behave linearly in the adoption of change. In fact, historical institutionalism assumes that policy-making systems tend to be conservative and tend to find ways to defend existing patterns of policy (Peters et al., 2005:1276). The inertia present within institutional arrangements discourages behavioural change (Barnes et al., 2004).

In this article the researcher navigates through key discourses that include organisational culture and context, and the structural form of governance and participatory democratic 
values. The assumption put forward is that universities have an inherent role to play in serving the public good. As Barnett asserts, "higher education can better assist the wider world in living at ease with super complexity by itself becoming an institution for the creation of new frames of understanding" (Barnett, 1999:69). This article posits that these "new frames" should include the university's approach to governance.

The article focuses on the study of the concepts of shared or cooperative governance. Statutory shared governance arrangements can be seen as an attempt to legislate and regulate public decision-making practice (Boland, 2005). The research argues for the strengthening of the argumentative community to which Molander (2002) refers. As context, the research connects the dots between the role of the university and the public good and more deliberative democracy through the shared governance model. The university's contributions to broader social goals such as equity and justice, as well as the way it effectively positions itself as an institutional site for the promotion of democratic citizenship, are important manifestations of its service to society (Boland, 2005; Morrow, 1998). Student participation in the governance process can be a powerful means to foster meaningful engagement while strengthening the values of political democracy within universities (Boland, 2005:207). This sentiment is echoed by Planas et al., Menon and others in the way they value universities introducing democratic ideals, practices and values of participation, equity and social justice (Planas et al., 2013; Menon, 2005; Sultana, 2012; Gumport, 2000; Calhoun, 2006). In order to enable critical dialogues, "universities must move away from bureaucratic and hierarchical forms of governance to more open and flexible organisational structures that allow different perspectives to emerge" (Menon, 2005:179). Transparency and inclusiveness are essential to good governance (Bergan, 2004).

As mentioned, the research is hinged on the IAD framework that prioritises the action arena, and recognises the centrality of the actors' positionality, and the values and norms that affect relationships and interactions. The study implies that the governance process itself and the degree to which it is considered fair and just are as important as outcomes (Delbecq et al., 2013:389). "Fair processes may be desirable in all organisations, but they are of particular importance in normative organisations, such as colleges and universities, in which goals are unclear and the consequences of decisions are not easily assessed" (Deal \& Kennedy, 1982:108). Decisions made based on democratic principles are more likely deemed legitimate, and perceived legitimacy in turn renders voluntary compliance with social regulations more likely (Birnbaum, 2004:10, 12, 15).

The article makes use of the concepts of "hard" and "soft" governance. This analysis draws distinctions between interactional "soft governance" and rational "hard governance", which are two disparate ways to understand governance via attitudinal and structural changes respectively (Birnbaum, 2004). There is an overlap in Birnbaum's articulation of these concepts with Ostrom's IAD framework, because they both reflect on rules and norms and the actors' interplay and interaction. 
Furthermore, the article highlights the significance of institutional culture to good governance (Kezar, 2004; Kaplan, 2004). Cultural conditions specific to a campus may actually trump structural arrangements (Kaplan, 2004). Interpersonal dynamics and culture affect governmental processes (Taylor, 2013).

\section{Research design}

The findings of this article are based on the first-hand perspectives of informants (29) who witnessed the impact of the IF and were integrally involved in its operation as an innovative feature of governance pertinent to transformation at the case study university. The construct of shared governance is the lens through which the phenomenon of change is viewed.

The twenty-nine informants key to the data collection consisted of seventeen individuals who were affiliated with the university (four from management, eight from staff/unions, and three student representatives, among others). Thirteen of those interviewed were current or former IF members.

The researcher's preparation for the interviews included the use of protocols, interview guides and piloting. Corroboration through multiple data sources was utilised to correct for responses during the interviews that might be incomplete, and/or geared toward what the informant thought the investigator wanted to hear.

The data-gathering process endeavoured to anticipate issues relevant to ethical considerations. Full disclosure was practised with the respondents in terms of the purpose of the research and how the results were to be used. The researcher took care not to put participants at risk, requested their voluntary informed consent, and provided them the right to withdraw and the entitlement to privacy and anonymity.

A fact sheet was sent in advance of the interviews that underlined key aspects from the above, restating the purpose of the study and the researcher's code of conduct. Care to maintain the anonymity of the university and informants was prioritised throughout the research exercise.

A single case study institution was chosen as the core of the research design in which a qualitative methodology was employed. This was deemed most suitable because research of this kind intends to reveal important aspects of a complex process and to capture the nuance and essence of internal relationships.

The case study university embodies a bicameral governance structure typical of South African public universities. It was chosen for its historic role and its leadership's explicit commitments and declarations to pursue a trajectory toward democratic transformation. Semi-structured interviews were designed to reveal the results of the interposition of the IF within the bicameral governance structure. 


\section{Governance}

This article views transformation through the governance lens and cites authors who recognise the importance attached to higher education power relations (Bradshaw \& Fredette, 2009:124-125; Botas \& Huisman, 2012; Birnbaum, 1989). Sultana's work sees governance as the centrepiece of university identity and, along with others, highlights higher education governance as the key policy issue for the 21st century (Sultana, 2012). The mode of governance adopted by the university therefore illustrates a great deal about the institution, its values, management and strategies, and how it sees itself in relation to its different communities.

Universities have the potential to be critical sites for democratic citizenship (Boland, 2005). Shared governance provides the chance to "practise and nurture the habits of democratic life" (Boland, 2005:214). Universities are normative organisations that use the manipulation of symbols to regulate the comportment of its members (Birnbaum, 2004). A combination of political, collegial and symbolic processes influences the human aspects that give governance meaning (Kezar \& Eckel, 2004). For these reasons, universities have been called "laboratories for democracy" which implies that governance is understood more as value-laden than technocratic (Sultana, 2012). The structures of governance should and can guard ideas, values and behaviour, but the structures on their own are not indicative of the main source of power (Kaplan, 2004:31). "Norms and structures tend to reinforce each other" (Peters et al., 2005:1279).

\subsection{Definitions and models}

This research focuses on institutional governance. Governance in Latin is gubernare, which is defined as to steer, direct, rule. The word is also derived from the Greek notion of steering, and in the modern sense, purposeful steering (Sultana, 2012:348). Governance is further defined as "the direction of the overall policies and resources of the organisation" (Delbecq et al., 2013:382). University governance, according to Fried et al. (2006), is "a set of laws, regulations, structures, norms and practices that constitute the framework for an institution to pursue its goals, objectives and policies in a coherent and coordinated manner" (Fried et al., 2006:98). This definition includes "explicit and implicit procedures that allocate to various participants the authority and responsibility for making institutional decisions" (Kaplan, 2004:23).

While there are other definitions, that of Magalhaes and Amaral (2009) holds meaning for this research. Their definition of governance is the "political management of rules and systems, both formal and informal, that drive values and norms affecting actors and constellations of actors' behaviours and attitudes" (Magalhaes et al., 2013:298). This research uses a definition that recognises the role of actors; their values and mindset are most pertinent to grasping the institution's promotion of an affinity toward the culture of change or transformation. Governance is where the identity of each university as a distinctive social and cultural institution is shaped (Bergan, 2005:113). 
Birnbaum's (2004) concepts of 'hard and soft' governance are important to this analysis. These concepts are in line with historical institutionalism which asserts that formal and informal arrangements within institutions lead to varying results. In fact, studies on governance stress the importance of the organisational structure, suggesting that if the structure or form is adjusted and improved, this change could lead to improved effectiveness.

Birnbaum defines 'hard' governance as "structures, regulations, and systems of sanctions in an organisation that defines authority relationships, prescribes certain organisational processes and encourages compliance with enacted policies and procedures" (Birnbaum, 2004:10). Others support these sentiments by focusing on rules, organisations and the ways in which rules shape different policy outcomes (Streeck \& Thelan, 2005). Within the IAD framework, rules are a means to achieve order and predictability. The governing structure is a crystallisation of agreements about the positions and possibilities of the actors within an organisation, in the context of their mutual relationships (Ostrom, 2011).

Birnbaum's 'soft' governance concept falls within the realm of the interactional aspect of governance. This side of governance "encompasses the systems of social connections and interactions in an organisation that help to develop and maintain individual and group norms" (Birnbaum, 2004:10). The 'soft' definition allows for cognitive transcendence or mindset change (Hall, 2008; Marcussen, 2000). Baldridge supports this position in his pivotal study on 'the human side of governance' (Baldridge, 1971:23-24). This accentuates the significance of interpersonal dynamics and cultures, factors that affect governmental processes the most (Kezar \& Eckel, 2004:381-382).

The research suggests it is important to develop an understanding of the 'soft' with the 'hard', the human side of governance (Kezar \& Eckel, 2004:381). "Policy emerges from interest groups, conflict, and values; it is embedded in people, not structures" (Kezar \& Eckel, 2004:382). In the end, interpersonal relations will shape the process and the results (Birnbaum, 2004; Gumport, 2000). The efforts of hard governance are likely to fail if the aims of the change conflict with soft governance.

The IAD Framework conveys the role of dissensus in the persistence of institutions. In this regard, the choices that actors make are based on their positions of power and accessibility to knowledge (Peters et al., 2005:1275). Dominant modes of decision-making are centred upon negotiation and consultation.

\subsection{Shared governance}

The analysis of the functioning and impact of the IF is based on the degree to which it appears to have democratised the university. Key to this is how the institution encompasses the principles of shared governance, democratic discourse, and inclusivity. 


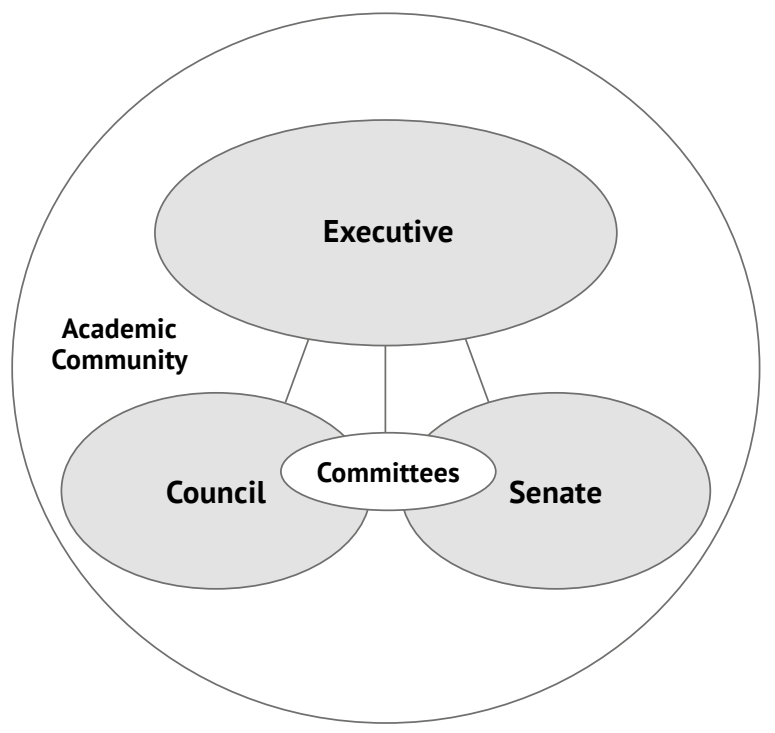

Figure 1: A model of shared governance

Source: Adapted from M. Taylor (2013:88)

As a consequence, shared governance is seen as responsive, internal governance that acknowledges the importance of 'the other' (Middlehurst, 2013:276; Bradshaw \& Fredette, 2009:389). Shared governance enhances transparency, involvement and greater plurality (Delbecq et al., 2013; Botas \& Huisman, 2012). This article addresses whether this internal governance structure is fit for purpose and covers areas where shared governance is seen to fall short of expectations (Middlehurst, 2013:75).

Shared or cooperative governance is one direction in which universities have gone to innovate and broaden decision-making and thus improve participation, morale and the quality of the educational experience. Furthermore, higher education's relationship with the public has begun to challenge the exclusivity of how decisions were made in the past (Minksova \& Pabian, 2011:186).

In short, the purpose of shared governance is to counter hierarchical power relations. The fundamental mission of universities is put forward as both serving and scrutinising society. They form laboratories for democracy models, in miniature (Sultana, 2012, Gerber, 2001:23). These cooperative forms are viewed in a positive light by many authors because universities become 'res publica' of their inclusivity of influence and ideas; horizontal accountability, ultimately, is positioned to serve society's needs (Bergan, 2004; Shattock, 2002; Jongbloed et al., 2008; Gerber, 2001).

Lastly, shared or cooperative governance allows for internal and external legitimacy for the university. This model fosters consultation and its positive effects on institutional knowledge (Birnbaum, 2004; Kezar \& Eckel, 2004:387; Delbecq et al., 2013).

Generally speaking, the literature underlines the importance of stakeholders within the university setting as a means of legitimation. "A university is seen as a complex institution composed of a variety of interest groups, each with its own particular interests and each, 
thus, potentially a legitimate, and equal, stakeholder in the governance of the university" (Morrow, 1998:387). The plurality of participants all have needs which must be mediated (Bradshaw \& Fredette, 2009:123).

Innovative governance within South African higher education will bring new insights to the field. This study addresses the current view that higher education governance is hierarchical, opaque and exclusive. It suggests the pursuit of a more deliberative democracy through the development of new models of shared governance. Such innovation could potentially help researchers rediscover the true meaning of a collegially governed university, by attaining the "ideals of a coincidence between the governors and the governed" (Morrow, 1998:389).

\subsubsection{The history of the institutional forum}

During the initial transformation phase within higher education institutions in South Africa, attention was given to instigating changes in governance structures and practices. Based on fundamental policy documents, such as the White Paper 3 (1997), this meant a more inclusive and equitable environment was to be put into place within South African public universities by re-establishing the decision-making process in line with cooperative governance. This signalled a rejection of apartheid-style authoritarianism.

The Institutional Forum (IF) is a statutory body based on precursors called 'Broad Transformation Forums' (Cloete \& Mohamed, 1995; Hall et al., 2002; Mohamed, 2002; Anonymous, 2010). These bodies were active during the throes of negotiation politics in the era immediately preceding South Africa's democratic dispensation. Broad Transformation Forums (BTFs) were critical entities during the twilight of the apartheid era because they addressed the serious crisis of legitimacy that resulted from a fragmented and racially fractured higher education system. The BTFs were aimed at "bringing about the redistribution of power and democratisation of key areas of South African society" (Cloete \& Mohamed, 1995; Mohamed, 2002:1; Anonymous, 2010; Harper et al., 2002; Cloete et al., 2002).

The first University Transformation Forum (UTF) was formed in 1991 at the University of the North during the period when Bantustan universities forcibly and geographically circumscribed and segregated large elements of black South Africans by ethnic group (Mohamed, 2002). BTFs emerged out of contested power relations in an era where community activists were increasingly looking beyond protest and reinventing society as part of the democratic movement for change in South Africa (Harper et al., 2002; Cloete \& Mohamed, 1995).

BTFs, as the antecedents of the modern IF, were steeped in the historical context of student activism, as students were arguably the most avid supporters of the University Transformation Forum concept. Moreover, the BTFs were formed due to student activism and advocacy for a more open, relevant and non-discriminatory higher education system. As Luescher illuminates in his work, student advocacy was centrally placed in the trajectory of the movement toward the democratisation of university governance in 
South Africa, because students challenged "hierarchical structures and oppressive social conventions" (Luescher, 2009:85).

The Forums, as early applications of cooperative governance, confronted the inadequacy of extant governance structures; they were to be inclusive and representative and would address issues of institutional culture, race and gender equity (Fourie, 1999; Mohamed, 2002). In some instances, BTFs superseded Councils (Cloete et al., 2002). They challenged old structures, replaced previous leaders and remade processes using a more participatory mould. Ultimately, BTFs were reconstituted as IFs, part of a more mainstream strategy to broaden participation in institutional governance.

After the end of apartheid and several years after the earlier experimentation with Forums as parallel bodies to pre-existing undemocratic governing bodies, the IF in the form examined by this research was established. In 1997, the South African Minister of Education, SME Bengu, sent a written communication to all South African public universities to inform them that they must establish an IF to accomplish the aim of transformation for higher education governance. This communiqué was followed by statutory requirements that were outlined in the Higher Education Act of 1997 (DOE, 1997b). This Act was based on core policy statements as outlined by the National Commission on Higher Education (NCHE, 1996) and the White Paper 3 (DOE, 1997a). The Higher Education Act provided for each university, through the facility of an Institutional Statute, to have its own discretion to further delineate more specific aspects of the IF, such as terms, membership composition and chairpersonship (DOE, 1997b:32). The IF would then become part of the new governing structure of the university, and be incorporated within the principally bicameral relationship of Council vis-à-vis Senate.

Unfortunately, South African core higher education policy instruments did not provide detailed guidance about the implementation of the IF. Legislation dictates that the institution must comply with national policy and the framework set up by the NCHE, the White Paper and the Higher Education Act (DOE, 1997b:176). While the policy documents laid out the principles, institutional autonomy was respected and honoured. In the end, flexibility and customisation of implementation was determined by individual institutional statutes written by the universities themselves. This is important to note in light of the lack of clarity that has characterised the role and function of the IF, which is indicated in this current analysis.

Although only a standing advisory committee, the IF was set up to play a specific role with regard to public universities in South Africa. The Forum's responsibilities could potentially have an impact on key aspects of transformation on university campuses because its possible functions were critical. They were outlined as: setting the change agenda, including race and gender equity plans, improving institutional culture as well as monitoring and assessing change, etc. (DOE, 1997b). 
Since the Higher Education Act of 1997, the Institutional Forum (IF) has exemplified the importance of the norm of shared governance that is a component of the democratisation of policy priorities within the objectives of the transformation process of South Africa's higher education sector. As a result of this governance innovation, the IF was positioned within the governance space traditionally dominated by the University Council as the supreme decision-maker within public universities. Through its status as advisory body, the IF was most directly responsible to that governing body. The influence of the IF was theoretically derived from its strong representation from major university constituencies.

The IF at the CSU consists of thirty members that include three co-chairs representing University Management, the Student Body and the Staff Associations or Unions. The Transformation Service Office (TSO) coordinates the IF's quarterly meetings. The TSO serves the strategic, financial and logistical needs of the IF's thirty members and their alternates. The shared co-chair approach purports to reinforce the principles behind cooperative or shared governance.

The actors in the social space of the IF could not be considered neatly homogenous. Various factors, such as university title, length of association with the university and personal experiences, affect the kind of contribution provided by IF members. Informants commented frequently on the differing levels of knowledge, exposure and resources that affected the viewpoints shared around the table. According to a student leader, "who is sent there [to the IF as member] makes a significant impact on how issues are articulated, how they are followed up and how they are debated in other platforms". Compared to other stakeholders, the students' situation was more precarious in that their tenure was shorter than the other stakeholders and the nature of their campus demands made their service on the IF more challenging. The membership terms for University Management, Unions, Senate and Council representatives were for longer durations as set out in the Institutional Statute (DOE, 2002).

\subsection{Student representatives}

Students as stakeholders were seen to have the strongest vested interest in transformation at the University. Student membership in the IF was decided by the Student Representative Council (SRC) who appointed representatives to the IF based on leadership roles within the SRC. The elected student designate as Student Transformation Officer within the $\mathrm{SRC}$, for example, was usually delegated to serve as one of three co-chairs of the IF, along with co-chairs selected from management and one from the various staff associations.

Informants claimed that the SRC was politically aware and "always pushing" (Senate representative). However, at the same time that students were deemed critical stakeholders, they were also accused of being disorganised, sporadically interested and even apathetic in past years (Council representative). Most observers of South African student activism bemoaned the history of post-democratic student activism as relatively "weak-kneed" and dominated by South African political parties. 
In addition, new students took time to 'warm up' to full participation within the Forum. In particular, if management encouraged the students to lead a meeting early in the year, i.e. "during their steepest learning curve" (as a former student co-chair asserted), it was difficult to be effectual, especially with only four regular meetings a year.

Students struggled to keep their voices coherent. University Management appeared to instead concentrate its energy on the Student Representative Council as an opening for communication channels. Therefore, despite the large numbers (one third of the total IF membership) the IF was not seen as a powerful tool for the amplification of the student voice as a gateway to influence other groupings.

Academic staff and union representatives thought that a positive, constructive and collaborative voice from students would push the university to do more. Students were seen to be in the best position to provide this charge and student stakeholders were enjoined to take a more active voice. They were to be the glue that affixed all stakeholder views into the mosaic that gave meaning and effectiveness to the IF, thus retaining the IF's cooperative governance character.

Student participation entailed an inherently transient membership vis-à-vis management and the Unions. "The cyclical nature of student participation made it difficult to keep conversation steady and consistent," asserted a student representative and former IF co-chair. Students rotating in and out, along with the prolonged discussion periods, diminished the value of the discourse and follow through.

In essence, the role of the student on the IF was highlighted as the most important of the stakeholders and with the most to contribute. "[Students] are going to smash demands at the [Vice Chancellor] VC's door, until he opens it up ... sometimes he opens it, sometimes not" (University official). On a number of occasions, management was accused of "unreasonable push back" and of machinations that weakened student involvement and information acquisition (Student and Union representative).

Students contributed spirited and unpredictable voices in the Forum debate. The irascibility of student participation was a common view of other key actors. One university staff member termed student participation as "inmates taking over the asylum". Students had the ability to render the meeting inquorate and could use their withdrawal from meetings as a bargaining chip. The strides that students could make within the structure of the IF were ultimately hard to pinpoint. University Management maintained control over the proceedings and students relied more heavily on other positions of power in the traditional governance structure.

\subsection{Management representatives}

The roles of the Vice Chancellor (VC) and Senior Management of the University were considered the most influential within the IF. Management was viewed as adopting quiet "backroom undercurrents of power" (Union representative). Issues such as the selection of agenda items for discussion, the formal transmission of the advisory report to the 
University Council and Management's role in raising (or diminishing) the visibility of the transformation issues discussed by the Forum were key to the centrality of the powerful role that it played. In addition, the direct line of coordination and supervision of the TSO by Management was relevant to the Forum's operation. Control was exercised exclusively within Management's domain and outside of the sphere of the other main categories of Forum stakeholders (i.e. Students and Staff Unions). The operation of the TSO was closely guided by the direct lines of authority from the TSO Director, the VC and the Deputy VC. Limited funding options for the TSO were also a constraining factor.

Data included perspectives on Management's apparent intention to soften or neutralise the IF's effects. Some respondents went so far as to term the Management-IF relationship as "the enemy from within" (University staff). Others pointed to feelings that powerful forces intended to push for the "death-knell of the Institutional Forum" (student representative) or at minimum to destabilise the Forum in order to minimise its effects (Union representative).

\subsection{Union (staff association) representatives}

The four union informants were cynical and angry in describing their experience with the IF. They were active and committed to their membership and to promoting the transformation of governance on campus. Union members' behaviour was conflictual. Their use of 'back channel' membership and/or observer status within other influential governing bodies or committees provided important outlets that could be used to communicate critiques about policy.

The Academic Staff Association (ASA) represented members of a small but influential governing body within the University, the Senate. The majority of the Senate members were full professors who, as senior-level academic staff, had earned their tenure and had served within the University for long periods; the Senate members were considered to have stakes in the 'old' system.

\subsection{The academic Senate}

Senate membership was, by all accounts, a homogenous body, overwhelmingly white and male at the CSU. Many were academics who had earned their degrees and university status during apartheid. The consensus from the data indicated that the Senate was a bastion of privilege and conservatism, "a cabal trying to resist change" (Senate representative).

The interview sessions did illustrate that this 'old style' conservatism was evolving, "and a good number wanted to see change" (Senate representative). However, the perceived lack of legitimacy of the Senate as a main governing body contributed adversely to the Forum's relationship to the other main decision-making body (the University Council) to which it has an advisory relationship. 


\section{The functioning of the Institutional Forum}

The IF's major function revolved around its relationship with the Council and the regular discussions of its stakeholder members.

\subsection{The Forum-Council relationship}

The University Council, as the supreme decision-making body on campus, was the governing body to which the IF was to provide advice. The IF's impact was indeed predicated on the integrity of this advisory status.

Findings yielded discoveries about the transformed nature of the University Council, issues of institutional legitimacy, confusion about roles and responsibilities, and slow receptivity to governance innovations. The over thirty members of the University Council at the CSU had also changed along with the governance landscape as per the Higher Education Act and its amendments (Hall et al., 2004; CHE, 2002). In order to instil a transformative element, the Act instituted a requirement for external membership on the Council. The Council's impact would depend on the membership, nominated by government and by university leadership.

The Council's make-up represented $60 \%$ external stakeholders who met to make decisions relevant to the interests of the university. Some of the informants indicated that the Council had indeed changed since 1994, into an entity that was more representative, diverse and progressive. At the CSU, the Chair and Vice Chair of the Council characterised the current Council as a more modern embodiment of post-apartheid democratic principles.

The Council at the CSU was understood to have been statutorily transformed. Some informants claimed the Council had always been receptive to change in understated ways that were never publicised during the apartheid era. Other informants would not describe the Council as a truly 'transformed' entity. The atmosphere of Council meetings was also described as "stock full of silence and intimidation" (Staff union representative). By many accounts, while the Council was ostensibly assembled to discuss and decide upon matters for the University at large, Council discussions were not interpreted as necessarily demonstrating an authentic participatory ethos similar to that promoted within the IF's meetings. While the Council membership was diverse, most felt participants were passive and arrived at their standpoints on a prima facie basis. Furthermore, the Council was seen to defer to the VC, "when in fact it is the VC who should be deferring to the Council" (University staff).

However, most stakeholders interviewed accepted the legitimacy of the Council. Unlike the Senate, the Council's presence was seen as a diverse body of nominated individuals who all shared a commitment to the common good of the University.

Informants expressed the opinion that the Council minimally regarded the work of the IF. "The Council treats the IF like a thorn in its side," a Union representative asserted. 
Controversy surrounded the form and content of the formal advisory report generated by the IF. Informants complained that the Council was not properly apprised of IF decisions in their full context so as to include the subtleties of arguments and attempts at consensus-building. The Institutional Statute was also unclear about whether the Council had an obligation to acknowledge and respond to any advice provided by the Forum.

The IF's structure supported its compliance-only status. "The illusion is created that it is supposed to have buy-in from all three main stakeholder groupings ... so the boxes to create that illusion are ticked," asserted a student representative. The advice that the Forum ultimately gave to Council was sporadic and received a mixed reception.

\subsection{Deliberative discourse}

Along with the Council-Forum relationship, the quality of discourse was an important element to the functioning of the Institutional Forum. The modus operandi of the IF centred on the principles of discussion and debate. The deliberative discourse was to bolster the traditional governance structure (Harper et al., 2002; DOE, 1997a; DOE, 1997b; DOE, 2002; Morphew, 1999; Cloete et al., 2002:182; DOE, 2008).

The IF was to provide a crucial social space for universities in South Africa. As envisioned by the NCHE and the White Paper, if the IFs worked properly, key issues would be debated at levels not debatable elsewhere. Ideally, brainstorming and robust debates would take place at Forum meetings. This would follow the trend established in the 1980s of deliberative as opposed to aggregative democracy as the most important development in normative democratic theory (CHE, 2007).

The quarterly meetings and the special sessions coordinated on a rotational basis by the three co-chairs of the IF became the settings for consensus-building and "collective will-formation" (Englund, 2000). If the agenda was well considered and the meetings well run, the Forum's resulting advice to Council would make a positive contribution to the climate of deliberation; hence, the gatherings would become an important consultative space (Anon., pers. comm., 2015; CHE, 2007:80). The Forum would become a manifestation of the culture of sense-making around difficult issues.

However, a common area of disappointment with the Forum was the lack of resolution that plagued the discussions. A Union representative called the discussions "talk shops without visible proof of results". Members were disillusioned because of the difficulty in placing specific discussion points on the agenda. Forum meetings were "like revolving doors with resolutions only intermittently starting to be addressed" according to an academic staff member.

Under closer examination, the normative value of deliberative democracy did not survive the operational constraints to achieving meaningful discourse. Members identified incidents of 'misinformation sharing' from Management. However, despite the complaints about tension, inquorate meetings, and difficult discourse, there were a few senior staff on the Forum who felt that "at least [the IF was] leading to a route somewhere". 


\subsection{Changing the governance status quo}

The majority of the informants were outspoken about their disappointment with the performance and impact of the Institutional Forum (IF). The primary reasons for this negative reaction stemmed from both confusion about the Forum's mandate and limitations placed by it. Policy documents set the bar high in terms of expectations for the IF and most stakeholders initially joined the advisory body with similarly high expectations.

The extent of the IF's role vis-à-vis university policy remained vague to its members, who interpreted the IF's purpose and responsibilities differently. Some members saw the Forum as operating within a narrow mandate that focuses more on procedural responsibilities, i.e. limited to providing a critique of processes and decisions already taken. Others at the University, for example, saw the merits of the senior staff appointments made, while the IF would only reasonably be expected to comment on the procedure. This meant that "the Vice Chancellor cannot appoint the Dean without due process ... and it is a consultative process" (University Management). The purpose of the IF therefore, was to voice its opinions on codes of conduct and advise whether legitimate consultation was conducted. This role implied that IF members needed to be patient and seek more gradual, palatable change. Consequently, the University's human resource department would effectively handle key aspects of senior appointments on its own, according to the Transformation Service Office staff. These observers looked to the Council, not the IF, to produce major policy impact on campus.

The 'toothless dog' metaphor surfaced in many interviews where informants described the IF's perceived powerlessness. Forum members experienced exasperation on many fronts, mainly because of the IF's advisory status, but also due to the lack of understanding from the Council itself about the weight of the IF's advice. Moreover, a number of Forum members were in disagreement about whether to narrow or broaden their ambit of influence within the University.

The IF members envisioned a broader range of issues to be considered during meeting discussions in order to achieve a more perceptible impact across campus. They foresaw the IF as promoting more immediate change in what some called a stultifying University climate.

\subsection{Governance and the institutional culture}

A significant objective of the IF was to promote change in the status quo of the institutional culture through the incorporation of more inclusive, transparent decision-making by the University Council of the CSU. The Institutional Statute stipulates this as one of the IF's main responsibilities. Informants for this research were not able to pinpoint many areas of success; instead they pointed to the toxic environment of the current institutional climate. In effect, the status of the IF at the CSU became nothing more than the often referenced 'toy telephone'. 
Informants felt that the leadership of the University was not genuinely behind the promotion of transformation. Interviews indicated a lethargic pace of change and the recognition that engrained cultures would continue to resist the pull of transformation. Some even questioned whether the DNA of universities would allow for change.

The status quo at the CSU was characterised as a culture of intolerance, bereft of hospitability and rife with intimidation. Staff, in particular, provided vignettes that attested to a steely stance adopted by the VC, and a repressive "culture of fear". Some staff members spoke of bullying via social media and the stifling of freedom of association (Anon., pers. comm., 2015). "You won't get fired here, you're going to fire yourself," an informant claimed as she referred to the repercussions that could result from staff who speak out (Anon., pers. comm., 2015). In many discussions with staff and students at the CSU, there was little belief that the mechanisms in place at the University, including the IF, could do much to address the toxic climate.

At the CSU, informants expressed anger at the lack of real impact after so long. Instead of real progress, University Management was "merely cycling, going down the road and back to the same place" - a view expressed by students and union staff. Other staff agreed and complained that while there may be some forward motion, the pace was much too slow and not aggressive enough.

The IF's impact on governance at the CSU was limited. It was clear that conservative institutional cultures ran counter to the tenets of shared governance.

\subsubsection{Observations}

The CSU's traditional governance structures appeared to struggle under the weight of the 'shocks' to the University, such as recent campus-wide protests. The insistent calls for Management to act swiftly and demonstrably to remove symbols of colonialism and other remnants of apartheid were a reminder of just how much transformation had yet to be achieved at the tertiary level in South Africa.

Theoretically, the IF could have served as a 'shock absorber' and a means to provide constructive advice to Council. The Forum, established as a manifestation of shared governance, was based on the values of inclusivity, with respect for stakeholder views through the promotion of deliberative democracy. The findings suggest that the IF was structurally hand-tied from confronting issues on campus during times of crisis. The same key actors who were expected to work within the new structure to promote change, were found to be constrained by their positions, interests and limited resources. In addition, the cultural ethos and pre-existing constructs of power limited the IF's effectiveness.

Table 1: Synthesis of views on Institutional Forum

\begin{tabular}{l|l}
\hline \multicolumn{1}{c|}{ Positive views } & \multicolumn{1}{c}{ Negative views } \\
\hline Legitimacy through diversity & Vague advisory authority \\
\hline IF as symbol of deliberative democracy & Weak administrative follow-through \\
\hline Promotion of inter-stakeholder dialogue & Low profile/Invisibility \\
\hline & Compliance mentality \\
\hline & Poor relationship with University Council \\
\hline
\end{tabular}




\section{The Forum's achievement and potential}

Overall, the IF's track record did not show substantial achievement. It was indeed true that its mere existence was a manifestation of shared governance which underscored the importance of diversity and rational discourse. The IF's role in monitoring the process followed for senior appointments was mentioned the most frequently as evidence of its positive contribution to governance transformation. Otherwise, members were cynical about the value of IF discussions and advice, asserting that the results were without consequence. Issues that came up during the IF sessions were perceived to be contained and ineffectual.

In the final analysis, a critical mass of informants felt there was much potential in the IF. They felt it should remain in place precisely because it was a product of cooperative governance that strives to bring together sides previously divided and/or in opposition. The IF was seen as a powerful but underutilised tool. The 'social space' it occupied needed to be recognised and manipulated in ways that would bring about changes in the University environment. The Forum represented the full range of possibilities: "advisory, transitory or revolutionary" (Harper et al., 2002:7). It remains to be seen whether the IF's potential will be realised in the midst of recent upsurges on campuses. In order to spur success, the cultural hurdles and the residual elements of conventional university hierarchy that continue to challenge shared governance would need to be broken down.

\section{References}

Anonymous (2010). [This source cannot be supplied, since the name of my case study university appears in the title.]

Baldridge, J.V. (1971a). Academic governance. Berkeley, C.A.: McCutchan Publishing Corp.

Barnes, W., Gartland, M. \& Stack, M. (2004). Old habits die hard: path dependency and behavioral lock-in. Journal of Economic Issues, 38(2), 371-377. https://doi.org/10.1080/00213624.2004.11506696

Barnett, R. (1999). Realizing the university. United Kingdom: McGraw-Hill Education.

Barnett, R. (2000). University knowledge in an age of supercomplexity. Higher Education, 40(4), 409-422. https://doi.org/10.1023/A:1004159513741

Bergan, S. (2004). Higher education governance and democratic participation: The university and democratic culture. In: S. Bergan (ed.). The university as res publica: Higher education governance, student participation and the university as a site of citizenship. Strasbourg: Council of Europe Publishing. 13-30.

Bergan, S. (2005). Higher education as a "public good and public responsibility": What does it mean? In: L. Weber \& S. Bergan (eds.). The public responsibility for higher education and research. Strasbourg: Council of Europe Publishing. 13-28.

Birnbaum, R. (2004). The end of shared governance: Looking ahead or looking back. New Directions for Higher Education, (127), 5-22. https://doi.org/10.1002/he.152

Boland, J. (2005). Student participation in shared governance: A means of advancing democratic values? Tertiary Education and Management, 11(3), 199-217. https://doi.org/10.1080/13583883.2005.9967147

Botas, P. \& Huisman, J. (2012). Deconstructing power in higher education structure: an analysis of representatives and roles in governing bodies. European Journal of Higher Education, 2(4), 370-388. https:// doi.org/10.1080/21568235.2012.746422 
Bradshaw, P. \& Fredette, C. (2009). Academic governance of universities: Reflections of a senate chair on moving from theory to practice and back. Journal of Management Inquiry, 18(2), 123-133. https://doi. org/10.1177/1056492608326320

Calhoun, C. (2006). The university and the public good. Thesis Eleven, 84(1), 7-43. https://doi. org/10.1177/0725513606060516

Cloete, N., Fehnel, R., Maassen, P., Moja, T., Perold, H. \& Gibbon, T. (eds.). (2002). Transformation in higher education: Global pressures and local realities in South Africa. Wynberg: CHET.

Cloete, N. \& Mohamed, N. (1995). Transformation in forums as revolutionary councils: Midwives to democracy or advisory councils for restructuring and innovation. Union of Democratic University Staff Association (UDUSA), Unpublished discussion paper.

Council on Higher Education (2007). Review of higher education in South Africa: Selected themes. Pretoria: Council on Higher Education.

Council on Higher Education Governance Task Team (2002). Promoting good governance in South African higher education. Policy Report. Pretoria: Council on Higher Education.

Deal, T.E. \& Kennedy, A.A. (1982). The rites and rituals of organizational life. Reading, Mass.: Addison-Wesley. 98-103.

Delbecq, A., Bryson, J.M. \& Van de Ven, A. (eds.). (2013). University governance: Lessons for an innovative design collaboration. Journal of Management Inquiry, 22(4), 382-392. https://doi.org/10.1177/1056492612471996

DOE (Department of Education) (1997a). Education White Paper 3: A Programme for the Transformation of Higher Education. General Notice 1196 of 1997. Pretoria: Department of Education.

DOE (1997b). Higher Education Act of the Republic of South Africa, No. 101 of 1997. Pretoria: Department of Education.

DOE (2002). Statute of the [Anonymous, CSU*]. Government Gazette 23837, (Notice 1199), 20 September. Pretoria: Government Printer. [ ${ }^{*}$ The name of my case study university]

DOE (2008). Report of the ministerial committee on transformation and social cohesion and the elimination of discrimination in public higher education institutions. Final Report, Pretoria: Government Printer.

Enders, J. (2012). The university and the public and private good. In: C. Teelken, E. Ferlie \& M. Dent (eds.). Leadership in the public sector: Promises and pitfalls. London: Routledge. 195-213.

Englund, T. (2000). Rethinking democracy and education: towards an education of deliberative citizens. Journal of Curriculum Studies, 32(2), 305-313. https://doi.org/10.1080/002202700182772

Fourie, M. (1999). Institutional transformation at South African universities: Implications for academic staff. Higher Education, 383, 275-290. https://doi.org/10.1023/A:1003768229291

Fried, J. (2006). Higher Education governance in Europe: autonomy ownership and accountability: A review of literature. In: J. Kohler \& J. Huber (eds.). Higher education governance: Between democratic culture, academic aspirations and market forces. Strasbourg: Council of European Publishing. 79-134.

Gerber, L. (2001). Inextricably linked: shared governance and academic freedom. Academe, 87(3), 22-24. https://doi.org/10.2307/40252014

Gumport, P.J. (2000). Academic restructuring: Organisational change and institutional imperatives. Higher Education, 39(1), 67-91. https://doi.org/10.1023/A:1003859026301

Hall, M. (2008). The objects of transformation in higher education. Social Dynamics: A Journal of the Centre for African Studies, 34(1), 74-85. https://doi.org/10.1080/02533950802078962

Hall, M., Symes, A. \& Luescher, T.M. (2002). Governance in South African higher education. Pretoria: Council on Higher Education. https://doi.org/10.4314/sajhe.v16i3.25214

Hall, M., Symes, A. \& Luescher, T.M. (2004). The culture of governance in South African public higher education. Journal of Higher Education Policy and Management, 26(1), 91-107. https://doi. org/10.1080/1360080042000182555 
Harper, A., Olivier, N., Thobakgale, S. \& Tshwete, Z. (2002). Institutional forums: An overview of their establishment and functioning at South African public higher education institutions. Sunnyside, South Africa: Centre for Higher Education Transformation.

Jongbloed, B., Enders, J. \& Salerno, C. (2008). Higher education and its communities: Interconnections, interdependencies and a research agenda. Higher Education, 56(3), 303-324. https://doi.org/10.1007/ s10734-008-9128-2

Kaplan, G. (2004). Do governance structures matter? New Directions for Higher Education, Fall, 127, 23-34.

Kezar, A. (2004). What is more important to effective governance: Relationships, trust, and leadership, or structures and formal processes? New Directions for Higher Education, Autumn (127), 35-46.

Kezar, A.J. \& Eckel, P.D. (2004). Meeting today's governance challenges: A synthesis of the literature and examination of a future agenda for scholarship. The Journal of Higher Education, 75(4), 371-399. https:// doi.org/10.1353/jhe.2004.0022

Lange, L. (2012). The public purposes of the university: a historical view, 1995-2012. In: B. Leibowitz (ed.). Higher education for the public good: views from the South. Staffordshire: Trentham Books. 45-57. https:// doi.org/10.18820/9781928357056/04

Luescher, T.M. (2009). Student governance in transition: University democratization and managerialism. A governance approach to the study of student politics and the case of the University of Cape Town. Unpublished doctoral thesis. UCT, Cape Town.

Magalhaes, A., Veiga, A., Amaral, A., Sousa, S. \& Ribeiro, F. (2013). Governance of governance in higher education: Practices and lessons drawn from the Portuguese case. Higher Education Quarterly, 67(3), 295-311. https://doi.org/10.1111/hequ. 12021

Magalhães, A.M. \& Amaral, A. (2009). Mapping out discourses on higher education governance. In: J. Huisman (ed.). International perspectives on the governance of higher education: Alternative frameworks for coordination. New York: Routledge. 182-197.

Marcussen, M. (2000). Ideas and elites: The social construction of economic and monetary union. Aalborg: Aalborg University Press.

Marginson, S. (2006). Putting 'public' back into the public university. Thesis Eleven, 84(February), 44-59. https://doi.org/10.1177/0725513606060519

Marginson, S. (2011). Higher education and public good. Higher Education Quarterly, 65(4), 411-433. https:// doi.org/10.1111/j.1468-2273.2011.00496.x

Menon, M. (2005). Students' views regarding their participation in university governance: implications for distributed leadership in higher education. Tertiary Education and Management, 11(2), 67-182. https://doi. org/10.1080/13583883.2005.9967145

Middlehurst, R. (2013). Changing internal governance: Are leadership roles and management structures in United Kingdom's universities fit for future? Higher Education Quarterly, 67(3), 275-294. https://doi. org/10.1111/hequ.12018

Minksova, L. \& Pabian, P. (2011). Approaching students in higher education governance: introduction to the special issue. Tertiary Education and Management, 17(2), 183-189. https://doi.org/10.1080/13583883.2011. 588720

Mohamed, N. (2002). History of institutional forums. Unpublished Report. Wynberg, South Africa: Centre for Higher Education Transformation.

Molander, B. (2002). Politics for learning or learning for politics. Studies in Philosophy and Education, 21(4), 361-375. https://doi.org/10.1023/A:1019878224617

Morphew, C. (1999). Challenges facing shared governance within the college. New Directions for Higher Education, (105), 71-79. https://doi.org/10.1002/he.10506

Morrow, W. (1998). Stakeholders and senates: the governance of higher education institutions in South Africa. Cambridge Journal of Education, 28(3), 385-405. https://doi.org/10.1080/0305764980280309 
National Commission on Higher Education (1996). An overview of a new policy framework for higher education transformation. Pretoria: Human Sciences Research Council.

Ostrom, E. (2011). Background on the institutional analysis and development framework. Policy Studies Journal, 39(1), 7-27. https://doi.org/10.1111/j.1541-0072.2010.00394.x

Peters, B.G., Pierre, J. \& King, D.S. (2005). The politics of path dependency: Political conflict in historical institutionalism. Journal of Politics, 67(4), 1275-1300. https://doi.org/10.1111/j.1468-2508.2005.00360.x

Planas, A., Soler P., Fullana, J. \& Pallisera, M. (2013). Student participation in university governance: The opinions of professors and students. Studies in Higher Education, 38(4), 571-583. https://doi.org/10.1080/ 03075079.2011 .586996

Pusser, B. (2006). Reconsidering higher education and the public good: the role of the public sphere In: W. Tierney (ed.). Governance and the public good. New York: SUNY Press. 11-27.

Shattock, M. (2002). Rebalance modern concepts of university governance. Higher Education Quarterly, 56(3), 235-244. https://doi.org/10.1111/1468-2273.00215

Singh, M. (2001). Re-inserting the "public good" into higher education transformation. Kagisano: Higher education discussion series, Summer, 1, 8-18.

Singh, M. (2011). The place of social justice in higher education and social change discourses. Compare: $A$ Journal of Comparative and International Education, 41(4), 481-494. https://doi.org/10.1080/03057925.201 1.581515

Streeck, W. \& Thelen, K. (2005). Beyond continuity: Institutional change in advanced political economies. Oxford: Oxford University Press.

Sultana, R.G. (2012). Higher education governance: a critical mapping of key themes and issues. European Journal of Higher Education, 2(4), 345-369. https://doi.org/10.1080/21568235.2012.719672

Taylor, M. (2013). Sharing governance in the modern university. Higher Education Quarterly, 67(1), 80-94. https://doi.org/10.1111/hequ. 12003

Tierney, W. (2006). The examined university: Process and change in higher education. In: W. Tierney (ed.). Governance and the public good. New York: SUNY Press. 1-10. 